\title{
Residential proximity to major roadways is associated with increased prevalence of allergic respiratory symptoms in children
}

\author{
Grzegorz Porebski', Magdalena Woźniak', Ewa Czarnobilska' \\ ${ }^{1}$ Department of Clinical and Environmental Allergology, Jagiellonian University Medical College, Krakow, Poland \\ Porebski G, Woźniak M, Czarnobilska E. Residential proximity to major roadways is associated with increased prevalence of allergic respiratory \\ symptoms in children. Ann Agric Environ Med. 2014; 21(4): 760-766. doi: 10.5604/12321966.1129929
}

\section{Abstract}

Introduction and Objective. Numerous epidemiologic studies have reported increased risk of allergic rhinitis and asthma in relation to 'western life-style', which represents diversity of factors. We hypothesized that residential proximity to major roadways, reflecting an exposure to traffic-related air pollution, is associated with prevalence of allergic respiratory symptoms in children.

Materials and Methods. A total of 8290 individuals of two age groups: 16 year olds and 7 year olds from Krakow, Poland were included. We used the Polish version of the International Study of Asthma and Allergy in Childhood supplemented with a question concerning the distance between a responder's house and a high traffic density road: below $200 \mathrm{~m}$, from 200-500 m, or more than $500 \mathrm{~m}$.

Results. Children and adolescents with a residential proximity closer to a major roadway had more frequent asthma-related symptoms in the last 12 months and at any time in the past. Consistent with the increased frequency of asthmatic symptoms, responders residing within 200 meters complained more often of sneezing, runny or blocked nose accompanied by itchywatery eyes and hay fever in comparison to responders who resided 200-500 meters from a major roadway. The lowest rate of nasal symptoms was observed in residents living in the distance to major roads ( $>500$ meters). The rate of positive answers decreased in a distant-dependent manner.

Conclusions. Our findings suggest an important spatial relationship between the distance from a major roadway and the evaluated respiratory symptoms. The results emphasize the need for more comprehensive air quality policies within urban areas with increased motor vehicle density.

I Key words

air pollution, allergic rhinitis, bronchial asthma, children, traffic

\section{INTRODUCTION}

Allergic respiratory diseases, bronchial asthma and allergic rhinitis, constitute one of the most prevalent childhood illnesses, therefore they are considered as crucial for public health. Their prevalence in developed countries has been increasing substantially over the past decades and has stabilized at the high level according to recent reports $[1,2]$.

Numerous epidemiologic studies have reported increased risk of allergic rhinitis and asthma in relation to such factors as urbanization, changes in life style including eating habits and higher standards of personal hygiene, progress in the treatment and prophylaxis of infectious diseases, particularly in industrialized countries. These evidences come mostly from studies comparing urban and rural populations $[3,4]$. Also, some other environmental factors were reported to affect an allergic immune response: lead and mercury induce oligoclonal T cell responses skewed toward type-2 reactivities [5], and endotoxins can be capable of acting as an adjuvants facilitating the initial sensitization to pollen allergens [6]. Several further studies have shown association between a burden of allergic diseases and ambient air pollution exposure measured as nitrogen dioxide [7], particulate matter [7, 8] or ozone [9], but others did not find such associations [10, 11]. These inconsistencies may be a result of differences in study

Address for correspondence: Grzegorz Porebski, Department of Clinical and Environmental Allergology, Jagiellonian University Medical College, Śniadeckich 10, 31-531 Kraków, Poland

E-mail: porebski@mp.pl

Received: 12 May 2013; accepted: 30 July 2013 design, as well as in methods for assessment of exposures and outcomes. Nevertheless convincing experimental evidence obtained in animals and human volunteers demonstrate a role of traffic-related air pollution in the development of allergic respiratory diseases by eliciting inflammatory reactions in the airways and enhancing immunologic responses to allergens [12, 13, 14]. A majority of the surveys focused on associations between traffic-related air pollutants and the development of asthma symptoms in children [6,15], but possible association with the common co-morbid condition, namely allergic rhinitis has not been often studied. Finally, children are particularly susceptible to air pollution, because they generally breathe more air per kilogram of body weight than adults, and also they are usually more active outdoor.

\section{OBJECTIVES}

We hypothesized that closer residential proximity to a major roadway, reflecting an exposure to traffic-related air pollution, would be associated with an increased prevalence of allergic respiratory symptoms. Therefore, the objective of our study was to assess if the frequency of positive answers to standardized questions about symptoms of bronchial asthma and allergic rhinitis was determined by the distance between responders' houses and a high traffic density road. Furthermore, we compared two groups differing in age children and adolescents, to analyze influence of age on the rates of symptoms. 


\section{MATERIAL AND METHODS}

A total of 8290 individuals were recruited from all public schools in Krakow, Poland. The study sample included all schoolchildren of two age groups: 16 year olds (4209 individuals) and 7 year olds (4081 individuals). Questionnaire assessments were used following the methodology proposed by the International Study of Asthma and Allergy in Childhood - ISAAC [16]. The Polish version of the ISAAC questionnaire was supplemented with a question concerning the distance between a responder's house and a high traffic density road, and the accepted limits were: below $200 \mathrm{~m}$, from 200-500 m, more than $500 \mathrm{~m}$. The group of patients in age of 16 filled in the questionnaire by themselves, whereas the questionnaire for the group of patients in age of 7 was answered by their caregivers. The answers to the following questions regarding asthmatic (A) and nasal (R) symptoms were used for the further analysis: A1. Have you ever had wheezing or whistling in the chest at any time in the past?; A2. Have you had wheezing or whistling in the chest in the last 12 months?; A3. In the last 12 months, has wheezing ever been severe enough to limit your speech to only one or two words at a time between breaths?; A4. Have you ever had asthma? A5. In the last 12 months, has your chest sounded wheezy during or after exercise?; A6. In the last 12 months, have you had a dry cough at night, apart from a cough associated with a cold or a chest infection?; R1. Have you ever had a problem with sneezing, or a runny, or a blocked nose when you did not have a cold or the flu?; R2. In the past 12 months, have you had a problem with sneezing, or a runny, or a blocked nose when you did not have a cold or the flu?; R3. In the past 12 months, has this nose problem been accompanied by itchy-watery eyes?; R4. Have you ever had hay fever?

The hypothesis about the influence of the distance between a place of residence and a major roadway on the frequency of symptoms was verified using chi-square test for trend with GraphPrism, version 6 (GraphPad Software, Inc. La Jolla, USA). Further comparisons were made between group of responders living $<200 \mathrm{~m}$ versus $200-500 \mathrm{~m}$ from a major roadway and subsequently between group of responders living $<200 \mathrm{~m}$ versus $>500 \mathrm{~m}$ from a major roadway. Results were presented as odds ratios (OR) with 95\% confidence intervals (CI) for a "yes" answer to the consecutive questions. Chi-square tests were used for other analyses. Significance was defined as a 0.05 using two-tailed tests. Data were analyzed with Statistica, version 10 (StatSoft, Inc., Tulsa, USA). The study protocol was approved by the Bioethics Committee of the Jagiellonian University.

\section{RESULTS}

In total, $44.8 \%$ of children aged 7 years $45.7 \%$ of adolescents aged 16 years enrolled in the study resided within 200 meters of a major roadway (the group “<200m"). $34.1 \%$ of children and $35.1 \%$ of adolescents were living in the distance $200-500$ meters (the group " $200-500 \mathrm{~m}$ ”). Finally, remaining $21.1 \%$ of children and $19.2 \%$ of adolescents were residing more than 500 meters from a major roadway (the group " $>500 \mathrm{~m}$ ") (Tab.1). The percentage of residents did not differ significantly between 7 years old and 16 years old responders in any of 3 considered distances. The proportions of gender were almost equal both in the studied population in total and in the subgroups, and ranged from 0.9 to 1.2 (Tab.1).
Table 1. Residential proximity from a major roadway. M/F, male/female proportion

\begin{tabular}{|c|c|c|c|c|}
\hline & \multicolumn{4}{|c|}{ the 7 year olds } \\
\hline & $\begin{array}{c}\text { All subjects } \\
n=4081(100 \%)\end{array}$ & $\begin{array}{c}<200 \mathrm{~m} \\
\mathrm{n}=1828(44.8 \%)\end{array}$ & $\begin{array}{c}200-500 \mathrm{~m} \\
\mathrm{n}=1392(34.1 \%)\end{array}$ & $\begin{array}{c}>500 m \\
n=861(21.1 \%)\end{array}$ \\
\hline \multirow[t]{3}{*}{$M / F$} & 1.1 & 1.2 & 1.1 & 1.0 \\
\hline & \multicolumn{4}{|c|}{ the 16 year olds } \\
\hline & $\begin{array}{c}\text { All subjects } \\
n=4209(100 \%)\end{array}$ & $\begin{array}{c}<200 \mathrm{~m} \\
\mathrm{n}=1924(45.7 \%)\end{array}$ & $\begin{array}{c}200-500 m \\
n=1479(35.1 \%)\end{array}$ & $\begin{array}{c}>500 m \\
\mathrm{n}=806(19.2 \%)\end{array}$ \\
\hline$M / F$ & 1.08 & 1.2 & 0.9 & 1.2 \\
\hline
\end{tabular}

\section{The questions about asthmatics symptoms at any time in the past}

The positive answer to the question about wheezing or whistling in the chest ever in the past (A1) was given by $30 \%$ of children and $15 \%$ of adolescents in the group " $<200 \mathrm{~m}$ ", followed by $22 \%$ of children and $11 \%$ of adolescents in the group " $200-500 \mathrm{~m}$ ", and respectively by $16 \%$ and $10 \%$ in the group " $>500 \mathrm{~m}$ ". In both age groups, the frequency of positive answers decreased significantly with the distance between responder's home and the closest major roadway (Fig. 1). Altogether, $24 \%$ of children versus $13 \%$ of adolescents answered chose an answer "yes" to the question A1 ( $<<0.05)$. The positive answer to the question about asthma ever in the past (A4) was given by $8 \%$ of children and $6 \%$ of adolescents in the group " $<200 \mathrm{~m}$ ", followed by $7 \%$ of children and $4 \%$ of adolescents in the group "200-500m", and respectively by $4 \%$ and $4 \%$ in the group " $>500 \mathrm{~m}$ ". In both age groups, the frequency of positive answers decreased significantly with the distance between responder's home and the closest major roadway (Fig. 1). Altogether, 7\% of children versus 5\% of adolescents answered "yes" to the question A4 ( $p<0.05)$.

\section{The questions about asthmatic symptoms in the last 12 months}

The positive answer to the question about wheezing or whistling in the chest in the last 12 months (A2) was given by $18 \%$ of children and $8 \%$ of adolescents in the group " $<200 \mathrm{~m}$ ", followed by $12 \%$ of children and $5 \%$ of adolescents in the group " $200-500 \mathrm{~m}$ ", and respectively by $8 \%$ and $5 \%$ in the group " $>500 \mathrm{~m}$ ". In both age groups, the frequency of positive answers decreased significantly with the distance between responder's home and the closest major roadway (Fig. 2.). Altogether, $14 \%$ of children versus $6 \%$ of adolescents chose an answer "yes" to the question A2 $(\mathrm{p}<0.05)$. The positive answer to the question about wheezing limiting a speech in the last 12 months (A3) was given by $4 \%$ of children and $3 \%$ of adolescents in the group " $<200 \mathrm{~m}$ ", followed by $2 \%$ of children and $1 \%$ of adolescents in the group " $200-500 \mathrm{~m}$ ", and respectively by $1 \%$ and $1 \%$ in the group " $>500 \mathrm{~m}$ ". In both age groups, the frequency of positive answers decreased significantly with the distance between responder's home and the closest major roadway (Fig. 2). Altogether, 3\% of children versus $2 \%$ of adolescents chose an answer "yes" to the question A3 $(\mathrm{p}<0.05)$. The positive answer to the question about wheezing during or after exercise in the last 12 months (A5) was given by $8 \%$ of children and $7 \%$ of adolescents in the group " $<200 \mathrm{~m}$ ", followed by $5 \%$ of children and $5 \%$ of adolescents in the group "200-500m", and respectively by $3 \%$ and $4 \%$ in the group " $>500 \mathrm{~m}$ ". In both age groups, the frequency of positive answers decreased significantly with the distance between responder's home and the closest major 


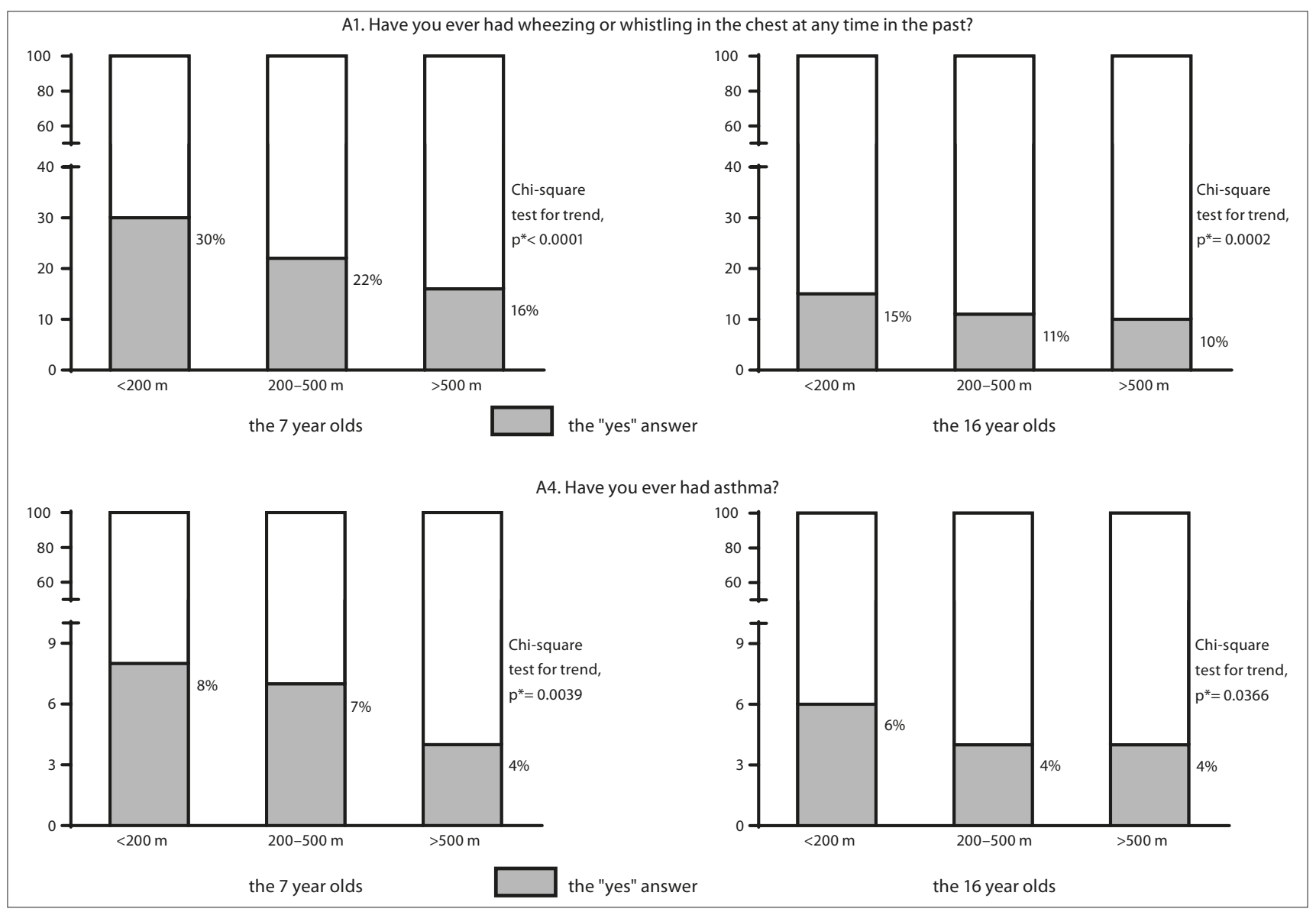

Figure 1. Percentage of positive answers to the questions about asthmatics symptoms at any time in the past according to residential proximity from a major roadway *statistically significant

roadway (Fig. 2). Altogether, 6\% of children versus 6\% of adolescents chose an answer "yes" to the question A5 (a difference statistically not significant). The positive answer to the question about a dry cough at night in the last 12 months (A6) was given by $24 \%$ of children and $11 \%$ of adolescents in the group " $<200 \mathrm{~m}$ ", followed by $19 \%$ of children and $8 \%$ of adolescents in the group " $200-500 \mathrm{~m}$ ", and respectively by $13 \%$ and $7 \%$ in the group " $>500 \mathrm{~m}$ ". In both age groups, the frequency of positive answers decreased significantly with the distance between responder's home and the closest major roadway (Fig. 2). Altogether, $20 \%$ of children versus $9 \%$ of adolescents answered "yes" to the question A6 $(\mathrm{p}<0.05)$.

\section{The questions about nasal symptoms}

The positive answer to the question about a problem with sneezing, or a runny, or a blocked nose ever in the past (R1) was given by $38 \%$ of children and $25 \%$ of adolescents in the group " $<200 \mathrm{~m}$ ", followed by $30 \%$ of children and $22 \%$ of adolescents in the group " $200-500 \mathrm{~m}$ ", and respectively by $24 \%$ and $22 \%$ in the group " $>500 \mathrm{~m}$ ". In the 7 years old age group, the frequency of positive answers decreased significantly with the distance between responder's home and the closest major roadway (Fig. 3). Altogether, $32 \%$ of children versus $23 \%$ of adolescents chose an answer "yes" to the question R1 ( $\mathrm{p}<0.05)$. The positive answer to the question about a problem with sneezing, or a runny, or a blocked nose in the last 12 months (R2) was given by $35 \%$ of children and $25 \%$ of adolescents in the group " $<200 \mathrm{~m}$ ", followed by $28 \%$ of children and $21 \%$ of adolescents in the group " $200-500 \mathrm{~m}$ ", and respectively by
$23 \%$ and $21 \%$ in the group " $>500 \mathrm{~m}$ ". In both age groups, the frequency of positive answers decreased significantly with the distance between responder's home and the closest major roadway (Fig. 3). Altogether, $30 \%$ of children versus $23 \%$ of adolescents answered "yes" to the question R2 $(\mathrm{p}<0.05)$. The positive answer to the question about itchy-watery eyes in the last 12 months (R3) was given by $18 \%$ of children and $15 \%$ of adolescents in the group " $<200 \mathrm{~m}$ ", followed by $12 \%$ of children and $13 \%$ of adolescents in the group " $200-500 \mathrm{~m}$ ", and respectively by $9 \%$ and $11 \%$ in the group " $>500 \mathrm{~m}$ ". In both age groups, the frequency of positive answers decreased significantly with the distance between responder's home and the closest major roadway (Fig. 3). Altogether, $14 \%$ of children versus $13 \%$ of adolescents chose an answer "yes" to the question R3 (a difference statistically not significant). Finally, the positive answer to the question about hay fever ever in the past (R4) was given by $19 \%$ of children and $18 \%$ of adolescents in the group " $<200 \mathrm{~m}$ ", followed by $15 \%$ of children and $16 \%$ of adolescents in the group " $200-500 \mathrm{~m}$ ", and respectively by $13 \%$ and $14 \%$ in the group " $>500 \mathrm{~m}$ ". In both age groups, the frequency of positive answers decreased significantly with the distance between responder's home and the closest major roadway (Fig. 3). Altogether, $16 \%$ of children versus $17 \%$ of adolescents answered "yes" to the question R4 (a difference statistically not significant).

Children residing within 200 meters of a major roadway had increased odds of asthmatic symptoms (questions A1-A6) compared both to children residing 200-500 meters (odds ratio within the range 1.2-1.6) and to children residing more 


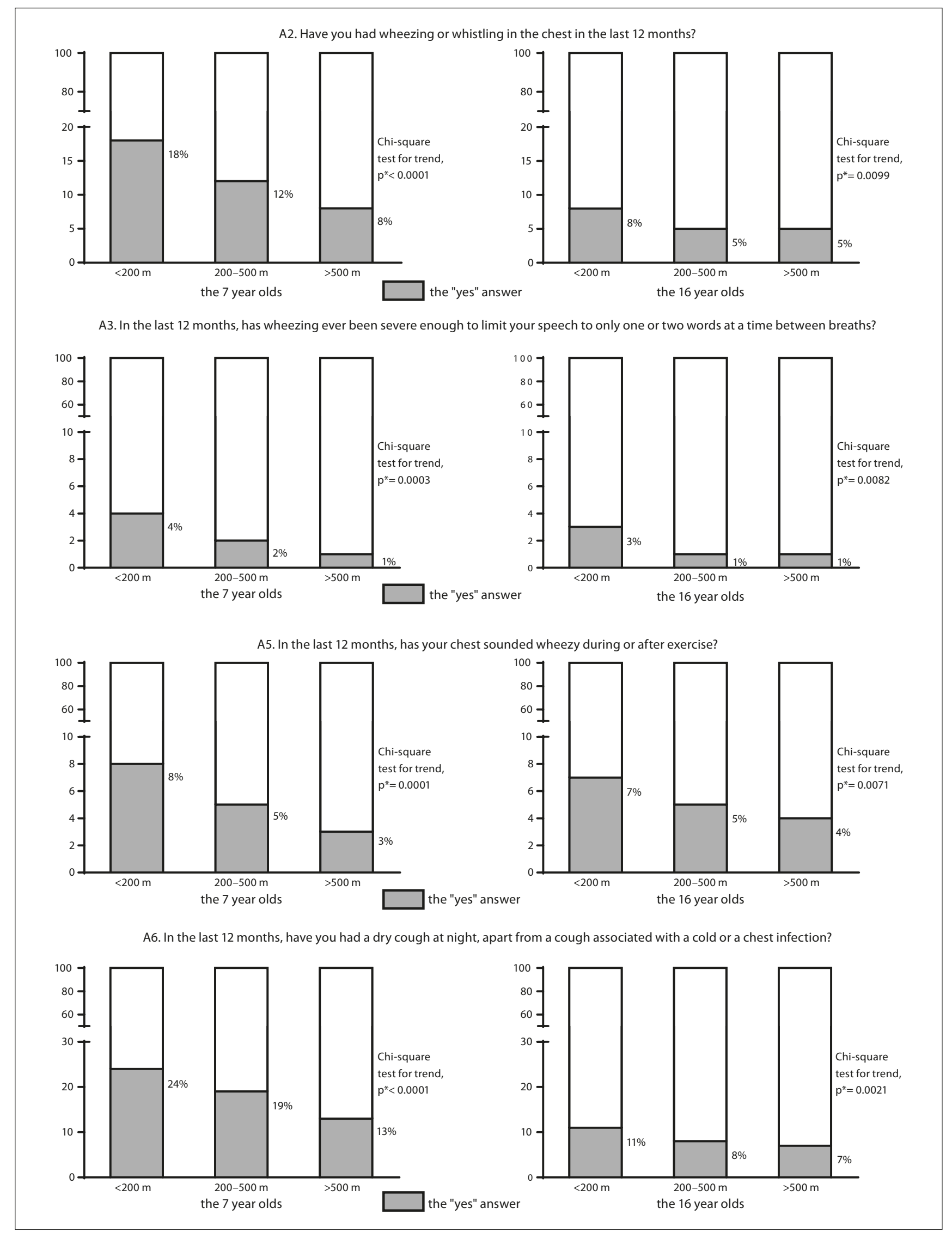

Figure 2. Percentage of positive answers to the questions about asthmatics symptoms in the last 12 months according to residential proximity from a major roadway *statistically significant 
R1. Have you ever had a problem with sneezing, or a runny, or a blocked nose when you did not have a cold or the flu?

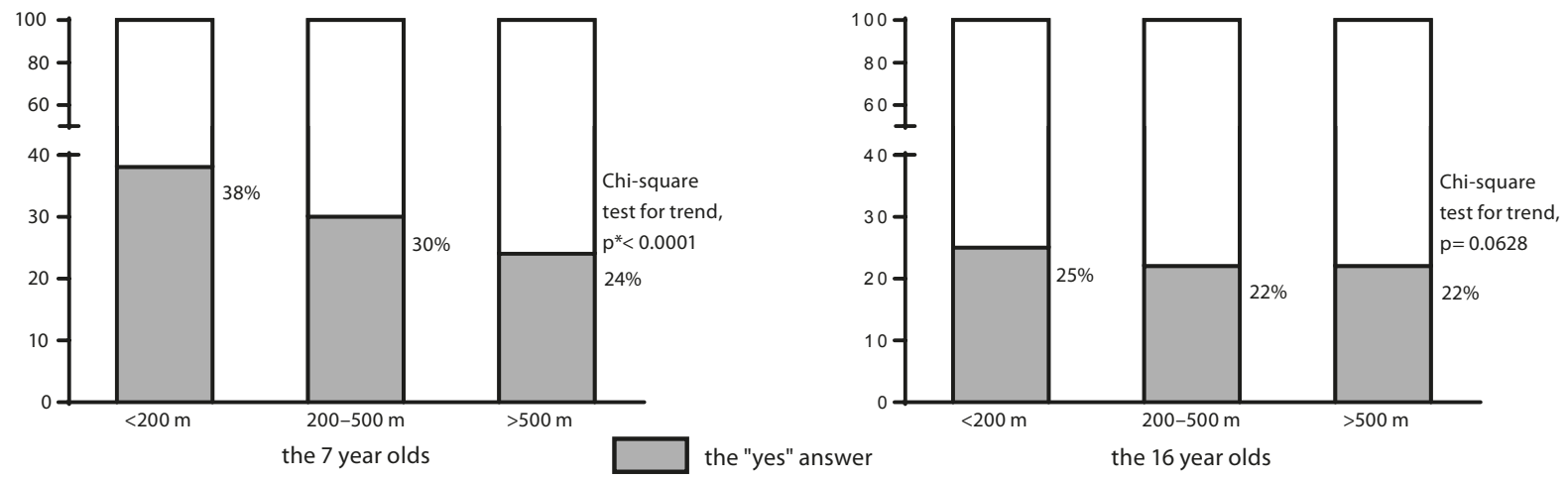

R2. In the past 12 months, have you had a problem with sneezing, or a runny, or a blocked nose when you did not have a cold or the flu?
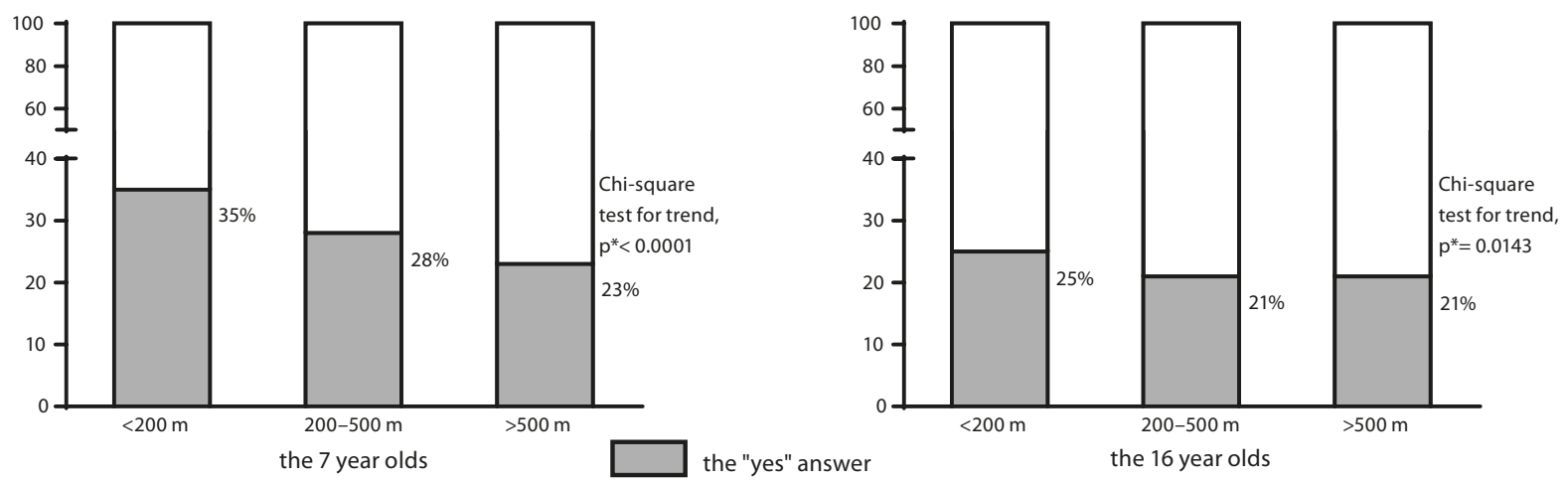

R3. In the past 12 months, has this nose problem been accompanied by itchy-watery eyes?
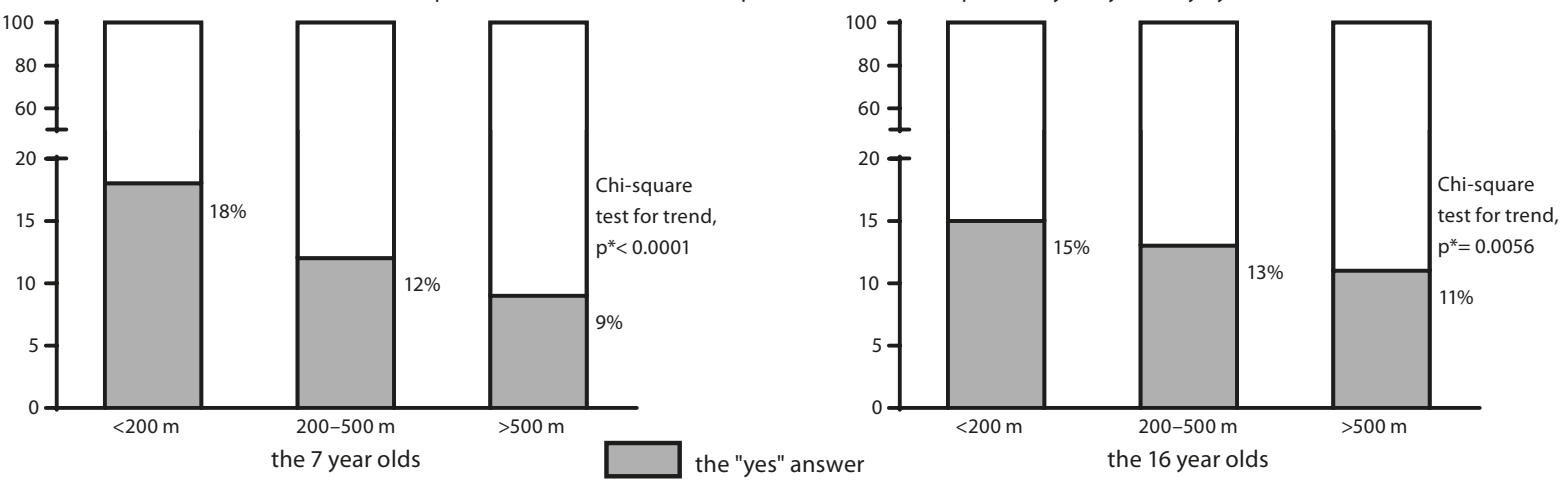

R4. Have you ever had hay fever?
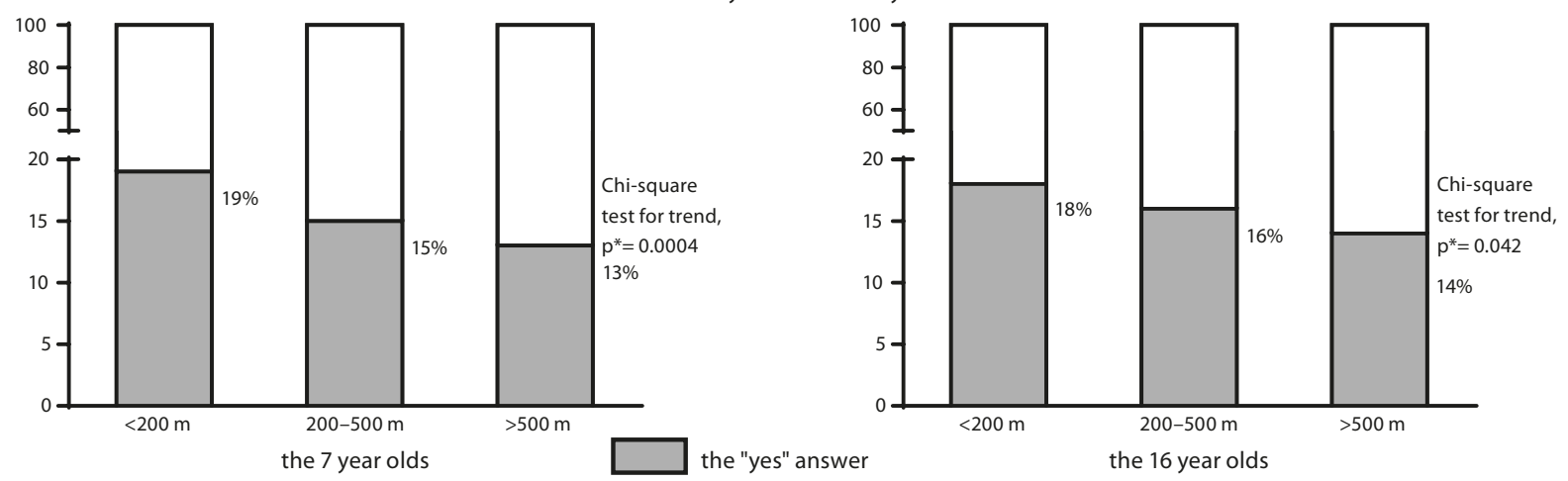

Figure 3. Percentage of positive answers to the questions about nasal symptoms according to residential proximity from a major roadway *statistically significant 
Table 2. Odds ratio (OR) with $95 \%$ confidence interval $(\mathrm{Cl})$ for positive answers to the questions about asthmatic symptoms for the group living within 200 m of a major roadway, related to the groups residing 200-500 $\mathrm{m}$ and further than $500 \mathrm{~m}$ from a major roadway. ORs higher than 2.0 are underlined. Ns, statistically not significant

\begin{tabular}{ccccc}
\hline & \multicolumn{2}{c}{ the 7 year olds } & \multicolumn{2}{c}{ the 16 year olds } \\
\hline question & $200-500 \mathrm{~m}$ & $>500 \mathrm{~m}$ & $200-500 \mathrm{~m}$ & $>500 \mathrm{~m}$ \\
\hline A1 & $1.5(1.3-1.8)$ & $\underline{2.3(1.8-2.8)}$ & $1.4(1.2-1.7)$ & $1.6(1.2-2.1)$ \\
\hline A2 & $1.5(1.2-1.9)$ & $\underline{2.5(1.8-3.4)}$ & $1.5(1.1-2.0)$ & $1.6(1.1-2.4)$ \\
\hline A3 & $1.6(0.9-2.8)^{\mathrm{ns}}$ & $\underline{5.7(2.0-15.9)}$ & $\underline{2.4(1.2-4.6)}$ & $\underline{2.6(1.0-5.1)}$ \\
\hline A4 & $1.2(0.9-1.6)^{\mathrm{ns}}$ & $\underline{2.0(1.3-2.9)}$ & $1.4(1.0-1.9)$ & $1.5(0.9-2.3)^{\mathrm{ns}}$ \\
\hline A5 & $1.4(1.0-2.0)$ & $\underline{2.5(1.6-3.9)}$ & $1.3(0.9-1.8)^{\mathrm{ns}}$ & $1.8(1.2-2.7)$ \\
\hline A6 & $1.4(1.1-1.6)$ & $\underline{2.0(1.6-2.6)}$ & $1.3(1.1-1.7)$ & $1.7(1.2-2.3)$
\end{tabular}

Table 3. Odds ratio (OR) with $95 \%$ confidence interval $(\mathrm{Cl})$ for positive answers to the questions about nasal symptoms for the group living within 200 m of a major roadway, related to the groups residing 200-500 $\mathrm{m}$ and further than $500 \mathrm{~m}$ from a major roadway. ORs higher than 1.5 are underlined. Ns, statistically not significant

\begin{tabular}{ccccc}
\hline & \multicolumn{2}{c}{ the 7 year olds } & \multicolumn{2}{c}{ the 16 year olds } \\
\hline question & $200-500 \mathrm{~m}$ & $>500 \mathrm{~m}$ & $200-500 \mathrm{~m}$ & $>500 \mathrm{~m}$ \\
\hline R1 & $1.4(1.2-1.7)$ & $\underline{1.9(1.6-2.3)}$ & $1.1(0.9-1.4)^{\mathrm{ns}}$ & $1.2(0.9-1.4)^{\mathrm{ns}}$ \\
\hline R2 & $1.4(1.2-1.7)$ & $\underline{1.8(1.5-2.2)}$ & $1.3(1.1-1.5)$ & $1.2(0.9-1.5)^{\mathrm{ns}}$ \\
\hline R3 & $1.5(1.2-1.9)$ & $\underline{2.3(1.7-3.1)}$ & $1.4(1.1-1.7)$ & $1.4(1.1-1.8)$ \\
\hline R4 & $1.3(1.0-1.5)$ & $\underline{1.6(1.3-2.0)}$ & $1.1(0.9-1.3)^{\mathrm{ns}}$ & $1.3(0.9-1.6)^{\mathrm{ns}}$ \\
\hline
\end{tabular}

than 500 meters from a major roadway (odds ratio within the range 2.0-5.7) (Tab. 2). A similar tendency was also noted in the group of adolescents (see Table 2). The 7 years olds living within 200 meters of a major roadway had increased odds of nasal symptoms (questions R1-R4) compared both to the 7 years olds residing 200-500 meters (odds ratio within the range 1.3-1.4) and to the 7 years olds residing more than 500 meters from a major roadway (odds ratio within the range 1.6-2.3) (Tab. 3). Again, a similar tendency was also noted in the group of adolescents (Tab. 3).

\section{DISCUSSION}

Traffic-related air pollutants are a composite mixture of nitrogen oxides, particulate matter including diesel exhaust particles (DEP), carbon monoxide, sulfur oxides and other volatile organic compounds.

Chronic exposure to higher levels of inhaled vehiclerelated emissions has been demonstrated to promote airway sensitization by modulating the allergenicity of airborne allergens [17] and by enhancing the production of the inflammatory cytokines interleukin 6 , interleukin 8 , and granulocyte macrophage-colony stimulating factor $[18,19]$.

Furthermore, some clinical studies have shown associations between traffic-related air pollution and aggravation of respiratory conditions, such as wheezing among asthmatic children $[20,21]$. Ishizaki et al. described the influence of pollution from automobile exhausts on onset of pollinosis among the residents in a densely cultivated area [22]. In the well-designed survey, Brown et al. [23] demonstrated that the associations depend on a distance between a place of residence and a major roadway. These findings are in line with our observations, and they warrant further studies and validation in other populations.
In our survey, we found that children and adolescents with a residential proximity closer to a major roadway had more frequent asthma-related symptoms in the last 12 months (Fig. 2 ) and at any time in the past (Fig. 1). Responders who resided within 200 meters of a major roadway had the highest rate of positive answers, followed by responders residing 200-500 meters, and further than 500 meters from a major roadway. This trend was observed for all questions about asthmatic symptoms (A1-A6) and was statistically significant. Our observations correspond to the results of a study conducted by Dales et al. [19]. They found that asthma related airway inflammation, was significantly related to increased roadway density within a 200-meter buffer area around a neighborhood. Similarly, other studies suggest that the concentration of DEP may be highest within 150 meters of a roadway [20], whereas no significant associations between roadway proximity and asthmatic symptoms were observed for subjects who lived further than 417 meters from a major roadway [23].

Consistent with the increased frequency of wheezing, a dry cough at night or whistling in the chest, responders residing within 200 meters had more often problems with sneezing, runny or blocked nose accompanied by itchy-watery eyes and hay fever (the questions R1-R4) in comparison to responders who resided 200-500 meters from a major roadway. The lowest rate of nasal symptoms was observed in residents living in the distance to major roads (> 500 meters) (Fig. 3). Again, the observed trend was statistically significant for all questions about nasal symptoms, apart from the question $\mathrm{R} 1$ in adolescents. Long-term exposure to air pollution was demonstrated to be associated with small airway remodeling, followed by lower respiratory tract symptoms [26], while nasal symptoms, such as sneezing, rhinorrhea or nasal congestion were studied to a lesser extent [27]. Our results confirm that upper respiratory tract is considerably affected by air pollution exposure, as well.

When comparing age groups, we found a higher rate of positive answers to all questions, except the questions R 3 and $\mathrm{R} 4$, in younger children. This difference can be explained by the smaller airway caliber in infancy, which was reported as an increasing risk for wheezing [28]. However, it is important to note that responders may have had higher or lower traffic exposures due to not only residential addresses but also addresses of day care facilities and schools. Younger children are expected to spend more time at home than adolescents, thus a residential address may have a higher impact on answers of children than adolescents. Finally, a possible explanation for the higher symptoms rates in the younger group might be a bias due to the method of collecting data. The 16 year olds were answering the questionnaire on their own, while the questionnaires for the 7 year olds were filled in by their parents, who might keep more recent memory of their children's symptoms.

We consider that strength of the study design was the large sample size, therefore a selection bias due to the distribution of potential confounders (e.g. unmeasured environmental factors and socio-cultural factors, such as family income and education level) may be more likely ruled out. Krakow is plagued by some of highest numbers of smog alert days in Poland, as well as heavy traffic, so we found it the appropriate place for this study. From a practitioner's point of view, it would be interesting to know how many times proximity to areas of high motor vehicle traffic increases the frequency of evaluated symptoms. We were able to pinpoint that responders who 
resided within 200 meters of a major roadway had substantially increased odds of asthmatic and nasal symptoms (Tab. 2, Tab. 3) in comparison to other responders. For instance, the frequency of severe wheezing in the last 12 months (the question A3) was almost 6 times higher in the group " $<200 \mathrm{~m}$ " compared to the group " $>500 \mathrm{~m}$ " of the 7 year olds.

As a matter of fact, this study does have its limitations. One should take into consideration that traffic density was assessed subjectively by responders and was not measured with objective method. Thus, we used self-reported traffic density, and self-reported health outcomes. However, traffic density and traffic-related air pollution were not directly measured, other studies have shown the distance to a major roadway to be a useful approximation of traffic-related air pollutant exposure $[29,30]$. The assessment of respiratory symptoms was based on questionnaire reports only, but the questionnaire was previously widely used to define respiratory outcomes in epidemiologic studies in children [16].

\section{CONCLUSIONS}

In summary, this study has shown that children and adolescents residing closer to a major roadway have an increased frequency of upper and lower respiratory tract symptoms, therefore living close to roadways with heavy traffic is a risk factor for developing symptoms of allergic respiratory diseases. Our findings further suggest an important spatial relationship between the distance from a major roadway and the evaluated respiratory symptoms. The results of this study emphasize the need for more comprehensive air quality policies within urban areas with increased motor vehicle density.

\section{Acknowledgments}

We thank Andrzej Stanisz for guidance in statistical analysis. We also thank all of responders who participated in the trial. This study was financed by the Municipal Council of Krakow.

\section{REFERENCES}

1. Asher MI, Montefort S, Bjorksten B, Lai CK, Strachan DP, Weiland SK, et al. Worldwide time trends in the prevalence of symptoms of asthma, allergic rhinoconjunctivitis, and eczema in childhood: ISAAC Phases One and Three repeat multicountry cross-sectional surveys. Lancet 2006; 368: 733-743.

2. Anandan C, Nurmatov U, van Schayck OC, Sheikh A. Is the prevalence of asthma declining? Systematic review of epidemiological studies. Allergy 2010; 65(2): 152-167.

3. Steinman HA, Donson H, Kawalski M, Toerien A, Potter PC. Bronchial hyper-responsiveness and atopy in urban, peri-urban and rural South African children. Pediatr Allergy Immunol. 2003; 14(5): 383-393.

4. Celik G, Sin B, Keskin S, Ediger D, Bavbek S, Mungan D, et al. Risk factors determining allergic airway diseases in Turkish subjects. J Asthma. 2002; 39: 383-390.

5. Heo Y, Lee WT, Lawrence DA. In vivo the environmental pollutants lead and mercury induce oligoclonal $\mathrm{T}$ cell responses skewed toward type-2 reactivities. Cell Immunol 1997; 179(2): 185-195.

6. Spiewak R, Skorska C, Prazmo Z, Dutkiewicz J. Bacterial endotoxin associated with pollen as a potential factor aggravating pollinosis. Ann Agric Environ Med. 1996; 3(1): 57-59.

7. Brauer M, Hoek G, Smit HA, de Jongste JC, Gerritsen J, Postma DS, et al. Air pollution and development of asthma, allergy and infections in a birth cohort. Eur Respir J. 2007; 29: 879-888.

8. Penard-Morand C, Raherison C, Charpin D, Kopferschmitt C, Lavaud F, Caillaud D, et al. Long-term exposure to proximity air pollution and asthma and allergies in urban children. Eur Respir J. 2010; 36: 33-40.
9. Penard-Morand C, Charpin D, Raherison C, Kopferschmitt C, Caillaud $\mathrm{D}$, Lavaud F, et al. Long-term exposure to background air pollution related to respiratory and allergic health in schoolchildren. Clin Exp Allergy. 2005; 35: 1279-1287.

10. Oftedal B, Brunekreef B, Nystad W, Nafstad P. Residential outdoor air pollution and allergen sensitization in schoolchildren in Oslo, Norway. Clin Exp Allergy. 2007; 37: 1632-1640.

11. Rosenlund M, Forastiere F, Porta D, De Sario M, Badaloni C, Perucci CA. Traffic related air pollution in relation to respiratory symptoms, allergic sensitisation and lung function in schoolchildren. Thorax. 2009; 64: 573-580.

12. Riedl MA. The effect of air pollution on asthma and allergy. Curr Allergy Asthma Rep. 2008; 8: 139-146.

13. Muranakam M, Suzuki S, Koizumi K, Takafuji S, Miyamoto T, Ikemori $\mathrm{R}$, Tokiwa H. Adjuvant activity of diesel-exhaust particulates for the production of IgE antibody in mice. J Allergy Clin Immunol. 1986; 77(4): 616-623.

14. Siegel PD, Saxena RK, Saxena QB, Ma JK, Ma JY, Yin XJ, Castranova V, Al-Humadi N, Lewis DM. Effect of diesel exhaust particulate (DEP) on immune responses: contributions of particulate versus organic soluble components. J Toxicol Environ Health A. 2004; 67(3): 221-231.

15. Patel MM, Hoepner L, Garfinkel R, Chillrud S, Reyes A, Quinn JW, et al. Ambient metals, elemental carbon, and wheeze and cough in New York City children through 24 months of age. Am J Respir Crit Care Med. 2009; 180: 1107-1113.

16. Asher MI, Keil U, Anderson HR, Beasley R, Crane J, Martinez F, et al. International study of asthma and allergies in childhood (ISAAC): rationale and methods. Eur Respir J. 1995; 8 (3): 483-491.

17. Devalia JL, Rusznak C, Davies RJ. Allergen/irritant interaction - its role in sensitization and allergic disease. Allergy 1998; 53 (4): 335-345.

18. Sydbom A, Blomberg A, Parnia S, Stenfors N, Sandström, T, Dahlen SE. Health effects of diesel exhaust emissions. Eur Respir J. 2001; 17(4): 733-746.

19. Bayram H, Devalia JL, Sapsford RJ, Ohtoshi T, Miyabara Y, Sagai M, et al. The effect of diesel exhaust particles on cell function and release of inflammatory mediators from human bronchial epithelial cells in vitro. Am J Respir Cell Mol Biol. 1998; 18 (3): 441-448.

20. Spira-Cohen A, Chen LC, Kendall M, Lall R, Thurston GD. Personal exposures to traffic-related air pollution and acute respiratory health among Bronx schoolchildren with asthma. Environ Health Perspect. 2011; 119: 559-565.

21. Escamilla-Nunez MC, Barraza-Villarreal A, Hernandez-Cadena L, Moreno-Macias H, Ramirez-Aguilar M, Sienra-Monge JJ, et al. Traffic-related air pollution and respiratory symptoms among asthmatic children, resident in Mexico City: the EVA cohort study. Respir Res. 2008; 9: 74 .

22. Ishizaki T, Koizumi K, Ikemori R, Ishiyama Y, Kushibiki E. Studies of prevalence of Japanese cedar pollinosis among the residents in a densely cultivated area. Ann Allergy. 1987; 58(4): 265-270.

23. Brown MS, Sarnat SE, Demuth KA, Brown LA, Whitlock DR, Brown SW, et al. Residential proximity to a major roadway is associated with features of asthma control in children. PLoS One. 2012; 7(5): e37044.

24. Dales R, Wheeler AJ, Mahmud M, Frescura AM, Liu L. The influence of neighborhood roadways on respiratory symptoms among elementary school- children. J Occup Environ Med. 2009; 51 (6): 654-660.

25. Holguin F, Flores S, Ross Z, Cortez M, Molina M, Molina L, et al. Trafficrelated exposures, airway function, inflammation, and respiratory symptoms in children. Am J Respir Crit Care Med. 2007; 176: 1236-1242.

26. Churg A, Brauer M, del Carmen Avila-Casado M, Fortoul TI, Wright JL. Chronic exposure to high levels of particulate air pollution and small airway remodeling. Environ Health Perspect. 2003; 111: 714-718.

27. Stankiewicz-Choroszucha BL, Wawrzyniak ZM, Lipiec A, Piekarska B, Kapalczynski WJ, Samoliński BK. Consequences of smoke inhalation in the 'Epidemiology of Allergic Diseases in Poland' project (ECAP). Ann Agric Environ Med. 2011; 18 (2): 420-428.

28. Martinez FD, Wright AL, Taussig LM, Holberg CJ, Halonen M, Morgan WJ. Asthma and wheezing in the first six years of life. The Group Health Medical Associates. N Engl J Med. 1995; 332: 133-138.

29. Li S, Batterman S, Wasilevich E, Elasaad H, Wahl R, Mukherjee B. Asthma exacerbation and proximity of residence to major roads: a population-based matched case-control study among the pediatric Medicaid population in Detroit, Michigan. Environ Health. 2011; 10: 34.

30. Nuvolone D, Della Maggiore R, Maio S, Fresco R, Baldacci S, Carrozzi $\mathrm{L}$, et al. Geographical information system and environmental epidemiology: a cross sectional spatial analysis of the effects of trafficrelated air pollution on population respiratory health. Environ Health. 2011; 10: 12 